\title{
Evaluation of salt tolerance ability in some fig (Ficus carica L.) cultivars using tissue culture technique
}

\author{
Hemaid Ibrahim Ahemaidan Soliman*, Mohamed R. A. Abd Alhady \\ Department of Plant Genetic Resources, Desert Research Center, El-Matariya 11753, Cairo, Egypt.
}

ARTICLE INFO

Article history:

Received on: June 02, 2017

Accepted on: July 17, 2017

Available online: November 09, 2017

\section{Key words:}

Fig (Ficus carica L.),

Micropropagation, Salinity,

$\mathrm{NaCl}$, Proline, Chlorophyll,

Mineral composition

\begin{abstract}
Ficus carica is one of the most important fruit species of Mediterranean countries. Egypt is one of the top countries in the world for the production of various cultivars of fig. The present work aimed to evaluate in vitro tolerance of five fig cultivars (i.e., Achtoy White, Masone Black, Zeiblly Red, Zeiblly Flair, and Shami Stihy) to $\mathrm{NaCl}$ on morphological characters and biochemical changes in multiplication stage. The in vitro shoots of fig cultivars were subcultured on Murashige and Skoog medium supplemented with 2 or $3 \mathrm{mg} / \mathrm{L}$ BAP and $0.5 \mathrm{mg} / \mathrm{L} 2 \mathrm{iP}$ and augmented with different concentrations of $\mathrm{NaCl}(0.0,2000,4000,6000,8000,9000,10000,11000$, and $12000 \mathrm{ppm})$ for 5 weeks under in vitro culture conditions. Number of newly formed shoots, shoot length, leaves number per shoot, necrosis $\%$, fresh and dry weights, chlorophyll content, and relative water content were recorded at regular intervals. The results revealed that the Masone Black and Shami Stihy cultivars were excellent compared other cultivars, followed by Achtoy White, Zeiblly Red, and Zeiblly Flair cultivars. $\mathrm{NaCl}$ concentrations of more than $10000 \mathrm{ppm}$ on Achtoy White and more than 11000 ppm of Zeiblly Red and Zeiblly Flair induced lethal effects. At 12000 ppm, $\mathrm{NaCl}$ had no adverse effect on the plantlets of cvs. Masone Black and Shami Stihy. Contents of $\mathrm{Na}+$ and $\mathrm{Cl}-$ were increased and loss of $\mathrm{K}+$ ions contents with increasing $\mathrm{NaCl}$ levels in all cultivars. In the present study, $\mathrm{K}+/ \mathrm{Na}+$ ratio was the highest in Masone Black and Shami Stihy while Zeiblly Flair cultivar was the lowest in $\mathrm{K}+/ \mathrm{Na}+$ ratio when the highest salt stress was applied.
\end{abstract}

\section{INTRODUCTION}

Ficus carica belongs to the Moraceae family. It contains more than 140 species categorized in 40 genera [1]. Figs have been cultivated for a long time in different places around the world as edible fruit. It originated in Western Asia and spread to the Mediterranean and some countries of the world. The most productive countries of edible figs are Egypt, Turkey, Morocco, Spain, Greece, California, Italy, Brazil, and other places characterized by mild winter and hot dry summer [2]. The cultivation of fig cultivars depending on the purpose of the use of fruit figs and fruits is eaten fresh, dried, and canned form [3]. F. carica originated from the Middle East, which is one of the first cultivated fruit species, and is currently an important crop around the world [4]. Now, the countries of the Mediterranean basin are growing in different varieties of figs. Fig cultivars differ in the morphological form of different leaf and fruit shape. The usual areas of cultivation of fig have decreased significantly; it has been reduced genetic variation due to the disappearance of many cultivars selected in the past. All grown cultivars are maintained by cuttings [5].

\section{*Corresponding Author}

Hemaid Ibrahim Ahemaidan Soliman,

Department of Plant Genetic Resources,

Desert Research Center,

El-Matariya 11753, Cairo, Egypt.

Email: hahemaid@yahoo.com
An increase in the salinity of soil water inhibits the germination and root elongation in most plants because it reduces water uptake, water use efficiency, and relative water content and inhibits $\mathrm{K}, \mathrm{Ca}$, and $\mathrm{NO}$ uptake by plant roots [6,7]. It has been shown that salinity reduces gas exchange, growth traits and yield, reduction in leaf chlorophyll, and photosynthesis [8]. In response to reductions in photosynthetic rate, salinity elevates antioxidant enzymes and proline content as a stress response to deal with increased levels of reactive oxygen species. Most plants under this strain are able to differentiate between $\mathrm{K}+$ ions in saline conditions and accumulate high levels of sodium to the detriment of the necessary $\mathrm{K}+$ and $\mathrm{Na}+$, which leads to loss of function of reaction-dependent $\mathrm{K}+$ leads to the $\mathrm{g}+$-induced toxicity. To obtain the effective use of the salt-affected soils, it is an important to identify saline fig genes and crop production significantly under salinity and benefit from genetic variation present in the genetic material to spread genotypes flexibility or to take advantage of this in the breeding program [9].

Tissue culture is one of the main tools in the field of plant biotechnology and called instead of cells, tissue, and organ culture under laboratory conditions. Salinity and drought-tolerant cultivars can be selected and evaluated using tissue culture [10,11]. Simple screening of plantlets by tissue culture under abiotic or biotic stress provides a study of many plant characteristics and evaluates these plants under specific conditions in a short time [12]. Furthermore, in vitro culture provides an important technique for studying the physiological effects of salt 
at the cellular level under known environmental conditions [13]. Biotechnology and tissue culture techniques are a powerful tool used to select plants under abiotic or biotic stress and to improve productivity traits in horticultural crops [14]. Meristem culture is the best method to produce large numbers of virus-free plants in a short period of time through in vitro propagation [15]. Tissue culture also provides a good advantage of maintained the conserved virus-free plants for different cultivars and easily exchanging them through laboratories between countries $[16,17]$.

The main aim of this study is to establish and examine the response of in vitro-propagated shoot tip explants of some cultivars of $F$. carica plantlets for salt tolerance and to determine the feasibility of screening F. carica plantlets for salt tolerance.

\section{MATERIALS AND METHODS}

\subsection{Explant Collection and Disinfection}

Shoot tip explants were collected from introduced of $F$. carica cvs. Achtoy White, Masone Black, Zeiblly Red, Zeiblly Flair, and Shami Stihy from the Arab Center for the studies of Arid Zones and Dry lands. Explants were washed under running tap water for $3 \mathrm{~h}$. Shoot tip explants $(0.5-1.0 \mathrm{~cm}$ length) were rinsed several times with sterile antioxidant solution (100 mg/L ascorbic acid and $150 \mathrm{mg} / \mathrm{L}$ citric acid) to avoid browning of the tissues. Surface sterilization of the explants was carried out under complete aseptic conditions in the laminar air flow hood. Subsequently, explants were sterilized by immersion for $25 \mathrm{~min}$ in sodium hypochlorite $2.5 \%(\mathrm{v} / \mathrm{v})$. After three subsequent washes in sterile double distilled water, explants were removed and rinsed 3-4 times with sterile antioxdant solution [18].

\subsection{Establishment of In Vitro Culture}

Sterilized shoot tip explants were cultured vertically on murashige and skoog (MS) medium [19] salts and vitamins containing different concentrations of 1.0-2.0 mg/L benzylaminopurine (BAP) combined with $0.05-0.1 \mathrm{mg} / \mathrm{L}$ naphthaleneacetic acid (NAA) and/or combined with $0.05-0.1 \mathrm{mg} / \mathrm{L}$ IAA to determine the best concentrations of growth regulators combinations for shoot formation. Before autoclaving nutrient media, the $\mathrm{pH}$ of the medium was adjusted to 5.8 , and the phytagel was added $0.25 \%$. All cultures were transferred to incubation room at $26 \pm 2^{\circ} \mathrm{C}$ and light intensity $\left(50 \mu \mathrm{mol} \mathrm{m}^{-} 2 \mathrm{~S}^{-} 1\right)$.

\subsection{Shoot Multiplication}

The shoots (length of 2-3 cm) were separated from establishment stage and then multiplied for eight subcultures on MS media containing different concentrations of N6 BAP alone or in combination with 0.5 $\mathrm{mg} / \mathrm{L}$ of N6- $\Delta^{2}$-isopentenyladenine (2ip). Shoots were transferred every 5 weeks on the same media.

\subsection{In Vitro Root Formation and Acclimatization}

Shoots derived from the multiplication stage were cultured on MS medium without hormones for 2 weeks to eliminate any effects of hormone. Then, shoots were transferred to MS medium supplemented with $100 \mathrm{mg} / \mathrm{L}$ myoinositol, $30 \mathrm{~g} / \mathrm{L}$ sucrose fortified with 1.0-2.5 mg/L indole butyric acid (IBA) alone, or combined with $0.0-0.5 \mathrm{mg} / \mathrm{L} \mathrm{NAA}$ or $0.0-0.5 \mathrm{mg} / \mathrm{L}$ IAA with or without $2 \mathrm{~g} / \mathrm{L}$ activated charcoal. The incubation of cultures under the same conditions used for shoot proliferation for five weeks. Rooted plantlets were removed from the culture medium, and it is washed gently under running tap water to get rid of the phytagel. The plantlets were transferred to plastic pots containing a mixture of peat moss and sand (1:1), and then, plantlets covered with transparent plastic bags under high humidity. After 4 weeks, polyethylene bags were completely opened, and after 4 weeks, more polyethylene bags were removed and plantlets were maintained under greenhouse conditions.

\subsection{Effect of Salinity}

\subsubsection{Growth characters}

Shoots (5-10 mm length) were subcultured onto MS medium containing 2.0 or $3.0 \mathrm{mg} / \mathrm{L} \mathrm{BAP}$ and $0.5 \mathrm{mg} / \mathrm{L} 2 \mathrm{iP}$ and supplemented with different concentration of $\mathrm{NaCl}$ at the level of $0.0,2000,4000,6000,8000$, $9000,10000,11000$, and $12000 \mathrm{ppm}$, respectively, to study the effect of different concentrations of $\mathrm{NaCl}$ on growth and development of in vitro shoots. Each treatment consists of four replicates and repeated each experiment twice. The data were calculated on shoot length, number of shoots/explant, and fresh and dry weights after 5-week growing period.

\subsubsection{Mineral composition}

Plant samples were dried at $500^{\circ} \mathrm{C}$ for $24 \mathrm{~h}$ using Thermolyne Muffle Furnace (6000 Furnace). The samples was heated with $10 \mathrm{ml} 2 \mathrm{~N}$ $\mathrm{HCl}$ on $80^{\circ} \mathrm{C}$ for $10 \mathrm{~min}$. The solution was prepared after filtered using Whatman filter paper \#42 and dilute it to $50 \mathrm{ml}$ with distilled water, and then, concentration of $\mathrm{Na}+$ and $\mathrm{K}+$ was determined after calibration with different concentration of $\mathrm{Na}+$ or $\mathrm{K}+$ solutions using Flame photometer 410 [20]. The concentration of $\mathrm{Na}+, \mathrm{K}+$, and $\mathrm{Cl}$ - was determined by flame emission spectrophotometry.

\subsubsection{Chlorophyll content}

About $0.5 \mathrm{~g}$ fresh weight sample of leaves was taken per replicate after 5-week exposure to salt stress, and the samples were extracted by acetone [21]. Samples were grinded in $2 \mathrm{ml}$ of $80 \%$ acetone using a pestle and mortar, and then, the sample extracted was transferred to $2.0 \mathrm{ml}$ Eppendorf tube and centrifuged at $15000 \mathrm{~g}$ for $2 \mathrm{~min}$. The supernatant was collected using pipette, and up to $3.0 \mathrm{ml}$ in $10 \mathrm{ml}$ measuring cylinder with an additional $80 \%$ acetone. The absorption spectra were measured by spectrophotometer (Smart Spec ${ }^{\mathrm{TM}} 3000$ Bio$\mathrm{Rad})$ at 510-665 nm absorbance, and chlorophyll $a$ and chlorophyll $b$ contents were calculated [22].

\subsubsection{Proline determination}

The proline content was measured in leaves derived from fig plantlets with $\mathrm{NaCl}$ treatments by measuring the amount of the colored product from interaction between proline with ninhydric acid [23]. The sample was read at $518 \mathrm{~nm}$ using a SmartSpec ${ }^{\text {TM }} 3000$ Bio-Rad spectrophotometer. The proline concentration in the sample was measured from a standard curve and calculated based on fresh weight.

\subsection{Statistical Analysis}

The data of all the study experiments were statistically analyzed as a factorial experiment. The Randomized Complete Block Design used to find the analysis of variance. Comparisons were made between the means through the least significant differences multiple range tests [24]. The data were analyzed using MSTAT software program.

\section{RESULTS AND DISCUSSION}

\subsection{In Vitro Propagation of Fig (F. carica L.)}

\subsubsection{Shoot induction}

F. carica cvs. Achtoy White, Masone Black, Zeiblly Red, Zeiblly Flair, and Shami Stihy were efficiently regenerated from shoot tip 
explants on MS medium containing different concentrations of BA as a cytokinin and combinations IAA or NAA as auxins.

Data recorded in Table 1 indicate that shoot tip explants of fig cvs. Achtoy White and Shami Stihy grown on MS medium with 1.0 $\mathrm{mg} / \mathrm{L} \mathrm{BA}+0.05 \mathrm{mg} / \mathrm{L}$ NAA gave the highest percentage of explants forming shoots (99\% and 97\%), respectively, compared with the other treatments (42-94\%) (Plate 1). However, the percentage of explants forming shoots was reached the highest value $99 \%$ of Zeiblly Red cultivar and $100 \%$ of Zeiblly Flair cultivar using $2.0 \mathrm{mg} / \mathrm{L} \mathrm{BA}$ $+0.1 \mathrm{mg} / \mathrm{L}$ NAA comparing with the other treatments $(38-97 \%)$. Furthermore, the percentage of explants forming shoots was reached the highest value $96 \%$ for Masone Black cultivar using $2.0 \mathrm{mg} / \mathrm{L} \mathrm{BA}$ $+0.1 \mathrm{mg} / \mathrm{L}$ IAA comparing with the other treatments (59-94\%). The mean number of axillary shoots formed explant (2.8 and 2.7) and mean length of the formed axillary $(3.0$ and $2.6 \mathrm{~cm})$ was the best treatment with $1.0 \mathrm{mg} / \mathrm{L}$ BAP + $0.05 \mathrm{NAA} \mathrm{mg} / \mathrm{L}$ for Achtoy White and Shami Stihy cultivars, respectively. However, the treatment containing 2.0 $\mathrm{mg} / \mathrm{L} \mathrm{BAP}+0.1 \mathrm{NAA} \mathrm{mg} / \mathrm{L}$ was the best treatment of mean number of axillary shoots (3.2 and 3.4) and mean length of the formed

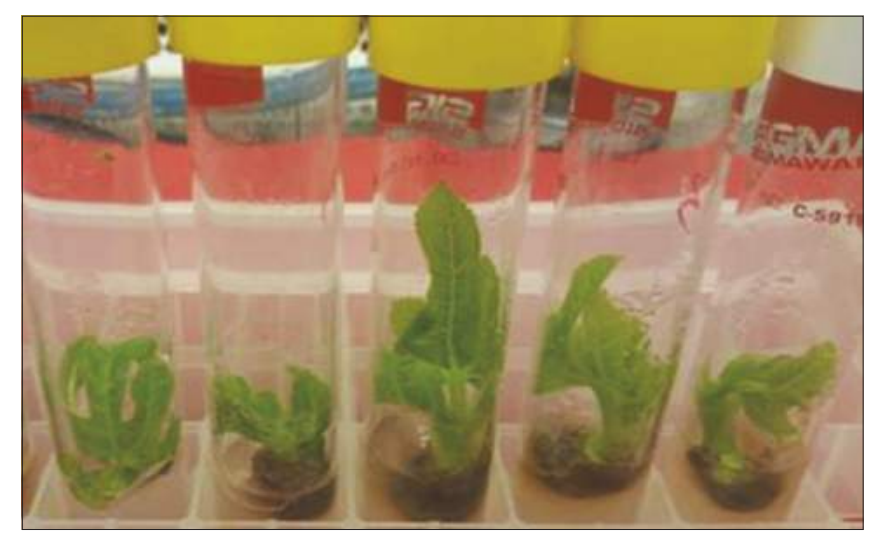

Plate 1: In vitro growth of Ficus carica cvs. Achtoy White, Shami Stihy,

Masone Black, Zeiblly Red, and Zeiblly Flair on MS medium supplemented with $1.0 \mathrm{mg} / \mathrm{L} \mathrm{BA}+0.05 \mathrm{mg} / \mathrm{L}$ NAA after 4 weeks. axillary $(2.8$ and $2.9 \mathrm{~cm}$ ) for Zeiblly Red and Zeiblly Flair cultivars, respectively. Furthermore, the mean number of axillary shoots formed explant (2.5) and mean length of the formed axillary $(2.4 \mathrm{~cm})$ was the best treatment with $2.0 \mathrm{mg} / \mathrm{L} \mathrm{BAP}+0.1 \mathrm{NAA} \mathrm{mg} / \mathrm{L}$ for Masone Black cultivar. Similarly, the highest value of mean number of shoots per explant was 2.99, 2.96, and 2.93 of cultivars Black Mission, Brown Turkey, and Brunswick, respectively, when shoot tips were cultured on MS medium containing 1.0 or $2.0 \mathrm{mg} / \mathrm{L}$ BAP in the presence of 0.5 or $1.0 \mathrm{mg} / \mathrm{L}$ NAA [7]. While, in vitro propagation was obtained from shoot tips and nodal explants on a medium based on MS supplemented with NAA, BA, and 2ip in three cultivars in fig cvs. Conadria, Abiad, and Sultani [18].

\subsubsection{Multiplication of shoot cultures}

Shoot cultures were multiplied by subculturing on MS media supplemented with several concentrations of BA even alone or in combination with $2 \mathrm{iP}$ were investigated for multiple shoot production in fig cultivars Achtoy White, Masone Black, Zeiblly Red, Zeiblly Flair, and Shami Stihy. The obtained data as summarized on Table 2 showed that shoot multiplication rates were significantly affected by the concentration of BA, as 6.5 shoots/explant were recorded for Masone Black cv., 7.2 shoots/explant for Zeiblly Red cv., and 7.5 shoots/explant for Zeiblly Flair cultivar using $2 \mathrm{mg} / \mathrm{L} \mathrm{BA}$ and $0.5 \mathrm{mg} / \mathrm{L}$, respectively (Plate 2). While, the mean number of shoots per explant of Achtoy White and Shami Stihy were significantly increased using the medium containing $3 \mathrm{mg} / \mathrm{L} \mathrm{BA}+0.5 \mathrm{mg} / \mathrm{L} 2 \mathrm{ip}$; it reached to 7.4-6.8, respectively, than the other treatments (Plate 3). It was observed that the low concentration of BAP in the medium leads to a decrease in shoot multiplication while the low concentration of BA and the combination of $2 \mathrm{iP}$ lead to elongation of shoots. The mean of shoots/explant were significantly increased of all cultivars using the medium containing $1 \mathrm{mg} / \mathrm{L} \mathrm{BA}+0.5 \mathrm{mg} / \mathrm{L} 2 \mathrm{ip}$; it reached to $2.5,2.4$, 2.7, 2.8, and $2.6 \mathrm{~cm}$ for Achtoy White; Masone Black; Zeiblly Red; Zeiblly Flair; and Shami Stihy, respectively, compared than the other treatments. Similarly, the best results for shoot multiplication and the rate of propagation of fig were 4.17, 3.42, and 5.0 over a 5-week period for Conadria, Abaid, and Sultani cultivars, respectively, on MS medium containing $3 \mathrm{mg} / \mathrm{L}$ BAP $+0.5 \mathrm{mg} / \mathrm{L} 2 \mathrm{iP}$ [18]. Furthermore,

Table 1: Effect of different concentrations of BAP, NAA, and IAA on shoots formation from shoot tip explants of $F$. carica cvs. Achtoy White, Masone Black, Zeiblly Red, Zeiblly Flair, and Shami Stihy after 5 weeks.

\begin{tabular}{|c|c|c|c|c|c|c|c|c|c|c|c|c|c|c|c|c|c|}
\hline \multicolumn{3}{|c|}{ Growth regulators (mg/L) } & \multicolumn{5}{|c|}{$\begin{array}{c}\% \text { of explant forming axillary } \\
\text { shoots }\end{array}$} & \multicolumn{5}{|c|}{$\begin{array}{c}\text { Mean number of axillary shoot/ } \\
\text { explant }\end{array}$} & \multicolumn{5}{|c|}{ Mean length of axillary shoots (cm) } \\
\hline BA & NAA & IAA & AW & MB & ZR & $\mathbf{Z F}$ & SS & AW & MB & $\mathbf{Z R}$ & $\mathbf{Z F}$ & SS & AW & MB & $\mathbf{Z R}$ & $\mathbf{Z F}$ & SS \\
\hline 1 & 0.05 & 0 & 99 & 55 & 84 & 87 & 97 & $2.8 \mathrm{~b}$ & $1.0 \mathrm{~g}$ & $1.5 \mathrm{e}$ & $1.5 \mathrm{e}$ & $2.7 \mathrm{~b}$ & $3.0 \mathrm{a}$ & $1.0 \mathrm{~h}$ & $2.0 \mathrm{e}$ & $2.0 \mathrm{e}$ & $2.6 \mathrm{~b}$ \\
\hline 2 & 0.05 & 0 & 94 & 68 & 90 & 91 & 92 & $2.0 \mathrm{~d}$ & $1.4 \mathrm{e}$ & $1.6 \mathrm{e}$ & $1.6 \mathrm{e}$ & $2.3 \mathrm{c}$ & $2.9 \mathrm{a}$ & $1.5 \mathrm{~g}$ & $1.8 \mathrm{f}$ & $1.9 \mathrm{e}$ & $2.5 \mathrm{c}$ \\
\hline 3 & 0.05 & 0 & 90 & 58 & 87 & 89 & 91 & $2.2 \mathrm{~d}$ & $1.1 \mathrm{~g}$ & $1.1 \mathrm{~g}$ & $1.1 \mathrm{~g}$ & $2.4 \mathrm{c}$ & $2.7 \mathrm{~b}$ & $1.2 \mathrm{~h}$ & $2.0 \mathrm{e}$ & $2.0 \mathrm{e}$ & $2.4 \mathrm{c}$ \\
\hline 1 & 0 & 0.05 & 65 & 80 & 72 & 70 & 76 & $1.5 \mathrm{e}$ & $1.8 \mathrm{e}$ & $1.0 \mathrm{~g}$ & $1.0 \mathrm{~g}$ & $1.0 \mathrm{~g}$ & $2.0 \mathrm{e}$ & $1.8 \mathrm{f}$ & $1.7 \mathrm{f}$ & $1.6 \mathrm{f}$ & $1.5 \mathrm{~g}$ \\
\hline 3 & 0 & 0.05 & 42 & 89 & 65 & 59 & 62 & $0.8 \mathrm{~h}$ & $2.1 \mathrm{~d}$ & $1.2 \mathrm{f}$ & $1.2 \mathrm{f}$ & $1.2 \mathrm{f}$ & $1.5 \mathrm{~g}$ & $2.1 \mathrm{~d}$ & $1.9 \mathrm{e}$ & $1.3 \mathrm{~g}$ & $1.0 \mathrm{~h}$ \\
\hline 1 & 0.1 & 0 & 94 & 59 & 95 & 97 & 89 & $2.6 \mathrm{~b}$ & $1.7 \mathrm{e}$ & $2.5 \mathrm{c}$ & $2.7 \mathrm{~b}$ & $2.2 \mathrm{~d}$ & $2.9 \mathrm{a}$ & $1.5 \mathrm{~g}$ & $2.7 \mathrm{~b}$ & $2.8 \mathrm{~b}$ & $2.4 \mathrm{c}$ \\
\hline 2 & 0.1 & 0 & 92 & 68 & 99 & 100 & 90 & $2.3 \mathrm{c}$ & $1.2 \mathrm{f}$ & $3.2 \mathrm{a}$ & $3.4 \mathrm{a}$ & $2.3 \mathrm{c}$ & $2.8 \mathrm{~b}$ & $1.3 \mathrm{~g}$ & $2.8 \mathrm{~b}$ & $2.9 \mathrm{a}$ & $2.3 \mathrm{~d}$ \\
\hline 3 & 0.1 & 0 & 95 & 62 & 97 & 92 & 94 & $2.4 \mathrm{c}$ & $1.5 \mathrm{e}$ & $2.7 \mathrm{~b}$ & $2.5 \mathrm{c}$ & $2.5 \mathrm{c}$ & $2.0 \mathrm{e}$ & $1.4 \mathrm{~g}$ & $2.6 \mathrm{~b}$ & $2.5 \mathrm{c}$ & $2.0 \mathrm{e}$ \\
\hline 1 & 0 & 0.1 & 64 & 89 & 50 & 65 & 77 & $1.0 \mathrm{~g}$ & $2.4 \mathrm{c}$ & $1.3 \mathrm{f}$ & $1.4 \mathrm{e}$ & $1.0 \mathrm{~g}$ & $1.9 \mathrm{e}$ & $2.2 \mathrm{~d}$ & $1.5 \mathrm{~g}$ & $1.8 \mathrm{f}$ & $1.8 \mathrm{f}$ \\
\hline
\end{tabular}

Mean followed by different letters differs significantly $(P<0.05)$. AW: Achtoy White, MB: Masone Black, ZR: Zeiblly Red, ZF: Zeiblly Flair, SS: Shami Stihy. F. carica: Ficus carica 
Table 2: Effect of different concentrations of cytokinins on multiplication of in vitro proliferation shoots F. carica cvs. Achtoy White, Masone Black, Zeiblly Red, Zeiblly Flair, and Shami Stihy after 5 weeks.

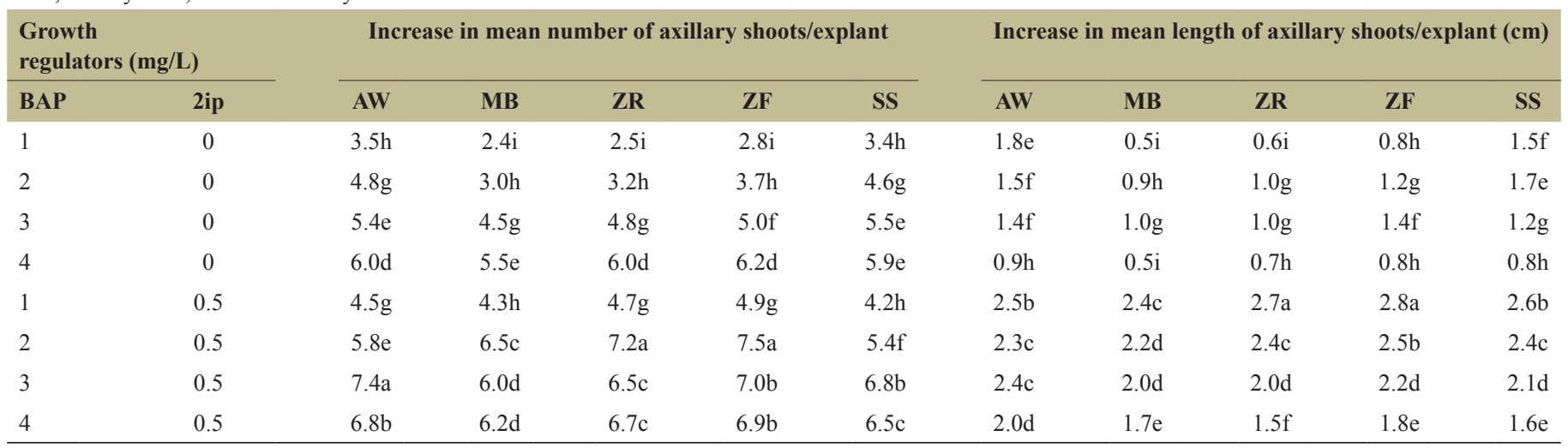

Mean followed by different letters differs significantly $(P<0.05)$. AW: Achtoy White, MB: Masone Black, ZR: Zeiblly Red, ZF: Zeiblly Flair, SS: Shami Stihy. F. carica: Ficus carica

Table 3: The efficiency of shoots forming roots of F. carica cvs. Achtoy White, Masone Black, Zeiblly Red, Zeiblly Flair, and Shami Stihy after growing on MS nutrient medium supplemented with different auxin concentrations.

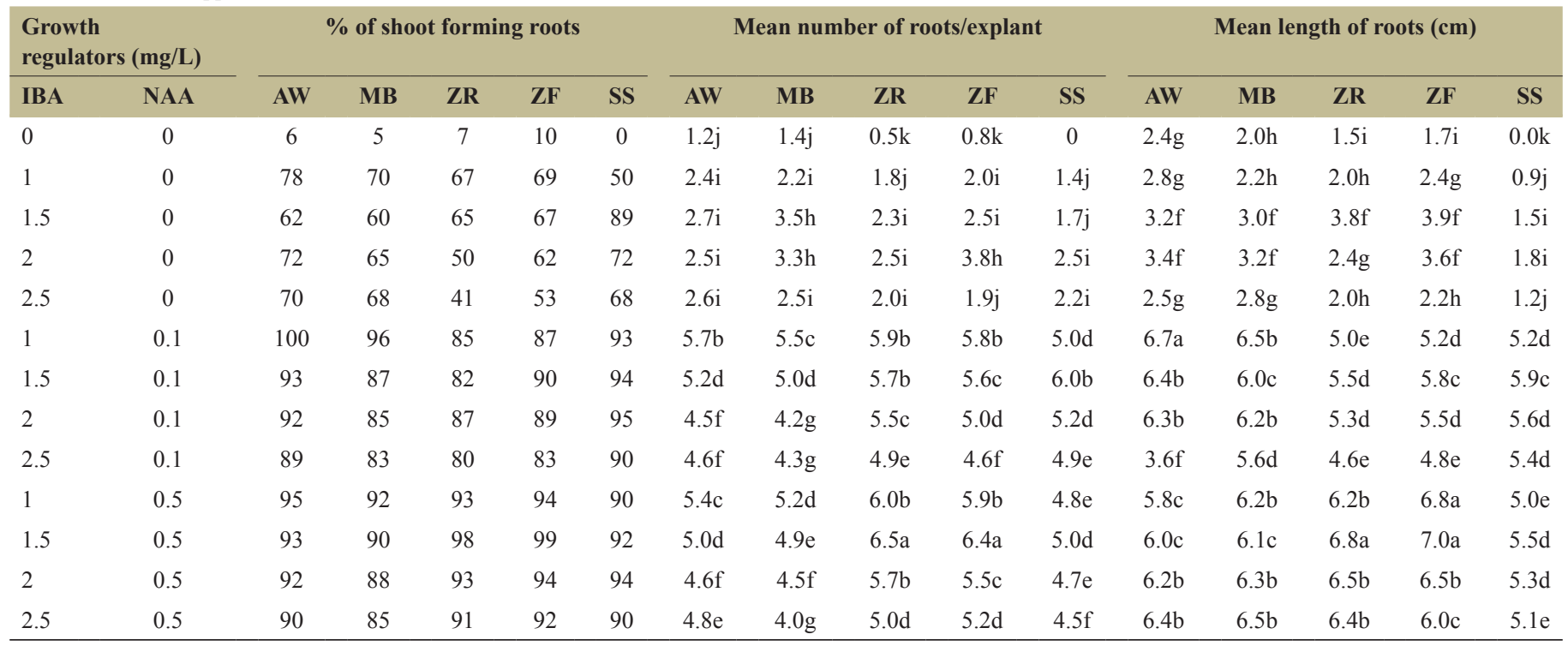

Mean followed by different letters differs significantly $(P<0.05)$. AW: Achtoy White, MB: Masone Black, ZR: Zeiblly Red, ZF: Zeiblly Flair, SS: Shami Stihy. F. carica: Ficus carica

the best shoot multiplication and increase in number of fig shoots were 7.25 and 6.75 for Black Mission and Brunswick cultivars, respectively, cultured on MS medium supplemented with $3 \mathrm{mg} / \mathrm{L} \mathrm{BAP}+0.5 \mathrm{mg} / \mathrm{L}$ 2iP, while cultivar Brown Turkey (6.85) on MS medium containing with $3 \mathrm{mg} / \mathrm{L} \mathrm{BAP}+0.5 \mathrm{mg} / \mathrm{L}$ kinetin [7].

\subsubsection{Rooting and ex vitro acclimatization}

The data seen in Table 3 explained that the combination of IBA and NAA gave better rooting response than IBA alone. The highest percentage of explants that produced roots (100-96\%) were observed on MS medium containing $1 \mathrm{mg} / \mathrm{L}$ IBA and $0.1 \mathrm{mg} / \mathrm{L}$ NAA with $2 \mathrm{~g} / \mathrm{L}$ activated charcoal for cultivars Achtoy White and Masone Black, respectively, and the percentage of shoots that formed roots was reached the highest value (98-99\%) for cultivars Zeiblly Red and Zeiblly Flair, respectively, using MS phytagel gelled nutrient medium supplemented with $1.5 \mathrm{mg} / \mathrm{L}$ IBA, $0.5 \mathrm{mg} / \mathrm{L} \mathrm{NAA}$, and $2 \mathrm{~g} / \mathrm{L}$ activated charcoal (Plate 4). While the percentage of shoots that formed roots and reached the highest value (95\%) was observed on MS medium containing $2 \mathrm{mg} / \mathrm{L} \mathrm{IBA,} 0.1 \mathrm{mg} / \mathrm{L}$ NAA, and with $2 \mathrm{~g} / \mathrm{L}$ activated charcoal for Shami Stihy. The mean number of roots (5.7 and 5.5) and mean length of roots formed on shoot

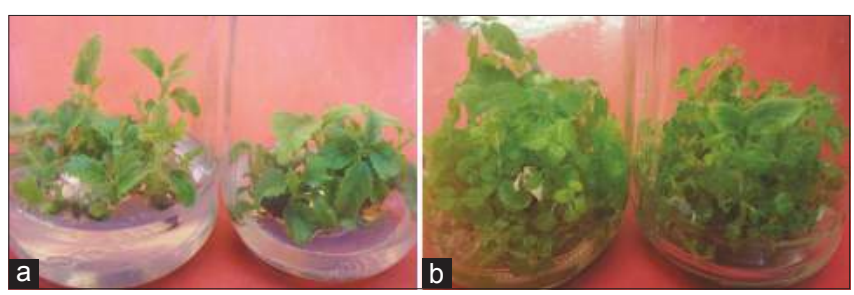

Plate 2: Shoot multiplication of Ficus carica cvs. Zeiblly Red and Zeiblly Flair (a): MS medium supplemented with $2 \mathrm{mg} / \mathrm{L} \mathrm{BAP}$, and (b): MS medium supplemented with $2 \mathrm{mg} / \mathrm{L}$ BAP and $0.5 \mathrm{mg} / \mathrm{L} 2 \mathrm{iP}$.

(6.7 and $6.5 \mathrm{~cm}$ ) on MS medium supplemented with $1.0 \mathrm{mg} / \mathrm{L}$ IBA and $0.1 \mathrm{mg} / \mathrm{L}$ NAA was significantly higher than the other treatments for Achtoy White and Masone Black cultivars, respectively. However, the mean number of roots (6.5 and 6.4) and the mean length of roots formed on the shoot $(6.8$ and $7.0 \mathrm{~cm})$ treated with $1.5 \mathrm{mg} / \mathrm{L} \mathrm{IBA}$ and $0.5 \mathrm{mg} / \mathrm{L}$ NAA for Zeiblly Red and Zeiblly Flair cultivars, respectively. Furthermore, the mean number of roots (6.0) and the mean length of 


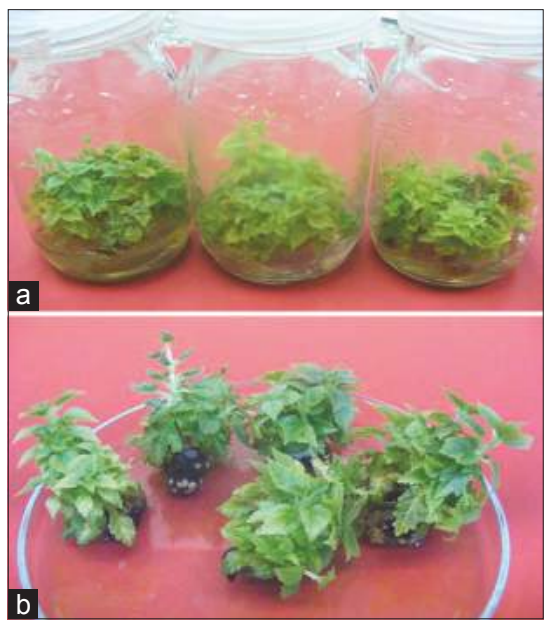

Plate 3: Shoot multiplication of Ficus carica L. cvs. Achtoy White, Masone Black, and Shami Stihy on MS medium supplemented with BAP and 2iP. (a): MS medium supplemented with $3 \mathrm{mg} / \mathrm{L} \mathrm{BAP}$ and $0.5 \mathrm{mg} / \mathrm{L} 2 \mathrm{PP}$. (b): MS medium supplemented with $2 \mathrm{mg} / \mathrm{L}$ BAP and $0.5 \mathrm{mg} / \mathrm{L} 2 \mathrm{iP}$.

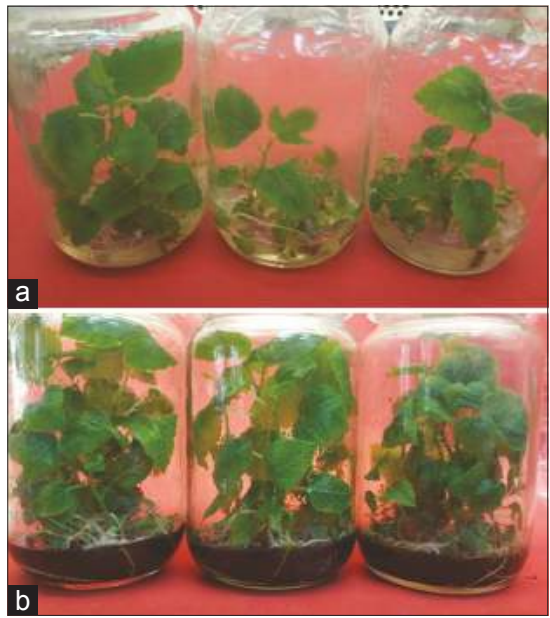

Plate 4: Rooting of Ficus carica on MS medium supplemented with $1.5 \mathrm{mg} / \mathrm{L}$ IBA and $0.5 \mathrm{mg} / \mathrm{L}$ NAA. (a): Without activated charcoal, and (b): With $2 \mathrm{~g} / \mathrm{L}$ activated charcoal.

roots formed on the shoot $(5.9 \mathrm{~cm})$ when treated with $1.5 \mathrm{mg} / \mathrm{L} \mathrm{IBA}$ and $0.1 \mathrm{mg} / \mathrm{L}$ NAA for Shami Stihy cultivar compared with the other treatments. Showed the previous work on in vitro fig plants that highest percentage of explants that produced roots $(80 \%)$ for fig shoots were obtained after 1 month in light on MS medium contained with $1 \mathrm{mg} / \mathrm{L}$ IBA $[25,26]$. Furthermore, the percentage of shoots that formed roots was the highest for cultivars black mission and brown Turkey using MS medium supplemented with $1.0 \mathrm{mg} / \mathrm{L}$ IBA and $0.5 \mathrm{mg} / \mathrm{L}$ NAA and incubated cultures in darkness for 1 week and transferred to light for 3 weeks. While the best rooting (97\%) was observed using MS medium contained with $1.5 \mathrm{mg} / \mathrm{L}$ IBA and $0.5 \mathrm{mg} / \mathrm{L} \mathrm{NAA}$ for cultivar Brunswick [7]. Plants produced from the rooting stage were transferred to a greenhouse, and after 8 weeks from transferring to the greenhouse, they were repotted into sterile soil consists equal parts of peat and sand (v/v) (Plate 5). Similarly, acclimatization of F. carica plantlets was transplanted into pots containing equal parts of peat and vermiculite $(\mathrm{v} / \mathrm{v})$ before transferring to the greenhouse after 4 weeks. After 8 weeks, they were repotted into sterile soil containing equal parts of peat and vermiculite $(\mathrm{v} / \mathrm{v})[15]$.

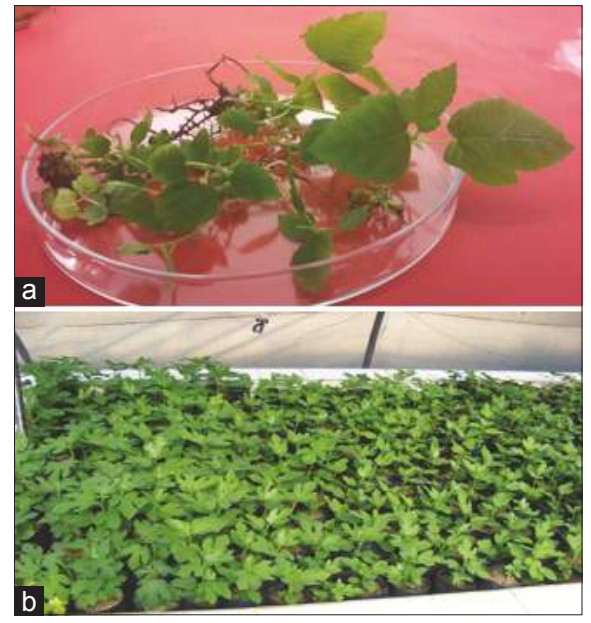

Plate 5: Rooting and ex vitro acclimatization of Ficus carica (a): Healthy plantlets with normal roots and (b): Acclimatization and establishment of ex vitro plants of Ficus carica cvs. Achtoy White, Masone Black, Zeiblly Red,

Zeiblly Flair, and Shami Stihy under greenhouse conditions.

\subsection{Salinity Stress}

\subsubsection{Growth parameters responses to salinity levels}

Microshoots produced from establishment stage were subcultured onto MS proliferation medium containing $2 \mathrm{mg} / \mathrm{L} \mathrm{BA}$ and $0.5 \mathrm{mg} / \mathrm{L}$ 2iP for Masone Black, Zeiblly Red, and Zeiblly Flair cultivars, and MS medium supplemented with $3 \mathrm{mg} / \mathrm{L} \mathrm{BA}+0.5 \mathrm{mg} / \mathrm{L}$ 2ip for Achtoy White and Shami Stihy cultivars containing different concentration of $\mathrm{NaCl}(0.0,2000,4000,6000,8000,9000,10000,11000$, and 12000 ppm). Data in Fig. 1 indicate that the application of the different concentrations of $\mathrm{NaCl}$ to $F$. carica cultivars Achtoy White, Masone Black, Zeiblly Red, Zeiblly Flair, and Shami Stihy after 5 weeks of treatments there were a decrease of in shoot length, shoot number, and number of leaves/shoot when increased salt concentrations in the media. Root length decreased from $2.90 \mathrm{~cm}$ compared to the control to $0.75 \mathrm{~cm}$ at $10000 \mathrm{ppm} \mathrm{NaCl}$ for Achtoy White cultivar, 2.75 and $2.85 \mathrm{~cm}$ for the control to 0.40 and $0.50 \mathrm{~cm}$ at $11000 \mathrm{ppm} \mathrm{NaCl}$ of Zeiblly Red and Zeiblly Flair cultivars, respectively. While root length was decreased from 3.45 and $2.65 \mathrm{~cm}$ for the control to 1.35 and 1.00 $\mathrm{cm}$ at $12000 \mathrm{ppm} \mathrm{NaCl}$ for Masone Black and Shami Stihy cultivars, respectively, and no rooting occurred when shoots were grown on MS medium contained $12000 \mathrm{ppm} \mathrm{NaCl}$ for the cultivars Zeiblly Red and Zeiblly Flair and $11000 \mathrm{ppm} \mathrm{NaCl}$ for Achtoy White, whereas the number of newly formed shoots of F. carica cultivar Achtoy White exhibited a significant decrease at $10000 \mathrm{ppm}$ of $\mathrm{NaCl}$ concentration, cultivars Zeiblly Red and Zeiblly Flair exhibited a significant decrease at $11000 \mathrm{ppm}$ of $\mathrm{NaCl}$ concentration, and cultivars Masone Black and Shami Stihy exhibited a significant decrease with $12000 \mathrm{ppm}$ of $\mathrm{NaCl}$ concentration. However, the highest value was recorded for the control (0.0) and $2000 \mathrm{ppm}$ of all cultivars compared with the other treatments. Results revealed that low level of salinity (control and $2000 \mathrm{ppm}$ ) in culture medium significantly enhanced shoot length and the number of newly formed shoots. High salinity levels from 4000 to $12000 \mathrm{ppm} \mathrm{NaCl}$ caused a decrease in shoot length and number of shoots. At the concentration of $11000 \mathrm{ppm} \mathrm{NaCl}$, it was lethal for Achtoy White cultivar but Zeiblly Red and Zeiblly Flair survived of that this concentration, and cultivars Masone Black and Shami Stihy were survived at $12000 \mathrm{ppm} \mathrm{NaCl}$. The necrosis rate was increased with increased $\mathrm{NaCl}$ in $\mathrm{MS}$ medium for most cultivars, but Achtoy 
White, Zeiblly Red, and Zeiblly Flair had slightly higher rate of necrosis (100\%) compared to Masone Black and Shami Stihy (30 and $32 \%$ ), respectively, with $12000 \mathrm{ppm}$ of $\mathrm{NaCl}$ concentration. Shoot length, shoot fresh, and dry weight significantly decreased under treatment with $\mathrm{NaCl}$ in the proliferation medium [27]. The addition of sodium chloride in the media of fig showed a negative effect on the growth of shoots and reduced the appearance of new formed shoots [8]. Similarly, shoot length and the number of newly formed shoots decreased with the increased salt concentration in the medium for three cultivars Black Mission, Brown Turkey, and Brunswick. Plantlets length ranged from 0.13 to $2.98 \mathrm{~cm}$, and the greatest plantlets length was found in $2 \mathrm{~g} / \mathrm{L}$ for the three cultivars and the smallest value was recorded at $11 \mathrm{~g} / \mathrm{L}$ compared with other the treatments; the number of newly formed shoots of fig cultivars Brown Turkey and Brunswick exhibited a significant decrease with $12 \mathrm{~g} / \mathrm{L}$ of $\mathrm{NaCl}$ concentration. However, the highest value was recorded for the control $(0.0)$ and 2 $\mathrm{g} / \mathrm{L}$ the other treatments. The percentage of necrosis increased with increase in $\mathrm{NaCl}$ concentration. For Black Mission survived at $12 \mathrm{~g} / \mathrm{L}$ $\mathrm{NaCl}$, while the death of plantlets at this concentration for the cvs. Brown Turkey and Brunswick both was observed [7].

\subsubsection{Fresh and dry weights}

The effect of salinity on fresh and dry weights showed significantly increased compared with the control treatment for the five cultivars as compared to all the other treatments. Afterward, a significant gradual decrease in fresh weight and dry weights took place at 4000, 8000, 10000,11000 , and $12000 \mathrm{ppm} \mathrm{NaCl}$ where the fresh and dry weight generally decreased with the increase in $\mathrm{NaCl}$ level in the medium, from 3.35 to $1.50 \mathrm{~g}$ at $4000 \mathrm{ppm} \mathrm{NaCl}$ to 1.56 and $0.72 \mathrm{~g}$ at $10000 \mathrm{ppm}$
$\mathrm{NaCl}$ of cv. Achtoy White, respectively (Table 4), whereas the fresh and dry weights decreased with the increase in $\mathrm{NaCl}$ level in the medium, from 3.58 to $1.89 \mathrm{~g}$ at $2000 \mathrm{ppm} \mathrm{NaCl}$ to 1.85 and $1.04 \mathrm{~g}$ at $12000 \mathrm{ppm} \mathrm{NaCl}$ of cv. Masone Black, respectively (Table 5). The results also showed that fresh and dry weight decreases when salt concentration increases in the medium, and the highest fresh weight (3.32 and $3.41 \mathrm{~g}$ ) and dry weight (1.61 and $1.68 \mathrm{~g}$ ) were obtained at $2000 \mathrm{ppm} \mathrm{NaCl}$, whereas the minimum fresh weight $(1.87$ and $1.92 \mathrm{~g}$ ) and dry weight $(0.74$ and $0.98 \mathrm{~g})$ was obtained at $11000 \mathrm{ppm} \mathrm{NaCl}$ for cvs. Zeiblly Red and Zeiblly Flair, respectively (Tables 6 and 7). Furthermore, the fresh and dry weights decreased with the increase in $\mathrm{NaCl}$ level in the medium, from 3.55 to $1.80 \mathrm{~g}$ at $2000 \mathrm{ppm} \mathrm{NaCl}$ to 1.75 and 0.92 at $12000 \mathrm{ppm} \mathrm{NaCl}$ for cv. Shami Stihy, respectively (Table 8). Reduced shoots affect fresh and dry weights as a result of increased $\mathrm{NaCl}$ level in the medium. Such reductions in shoot fresh and dry weights were also well documented [28].

\subsubsection{Chlorophyll content}

Chlorophyll a, b, and $\mathrm{a}+\mathrm{b}$ amounts decreased due to $\mathrm{NaCl}$ increased the concentration in the media. Maximum values of chlorophyll a (265.52 and $260.00 \mathrm{~g}^{-1} \mathrm{FW}$ ) and chlorophyll b were 104.62 and $100.54 \mathrm{~g}^{-1} \mathrm{FW}$ at the control in Masone Black and Shami Stihy cultivars, respectively. While the lowest content values of chlorophyll a and b were 250.75 and $90.00 \mathrm{~g}^{-1} \mathrm{FW}$ in cv. Zeiblly Red compared with other cultivars. Chlorophyll a/b ratio was decreased in the $F$. carica five cultivars with increased $\mathrm{NaCl}$ level. Chlorophyll $\mathrm{a} / \mathrm{b}$ ratio decrease was 1.35 in Masone Black cv and 1.36 in Shami Stihy cv at $12000 \mathrm{ppm} \mathrm{NaCl}$. Furthermore, chlorophyll a/b ratio decrease was 1.62 when 10000 ppm $\mathrm{NaCl}$ in Achtoy White cv., and chlorophyll a/b ratio decrease was 1.30

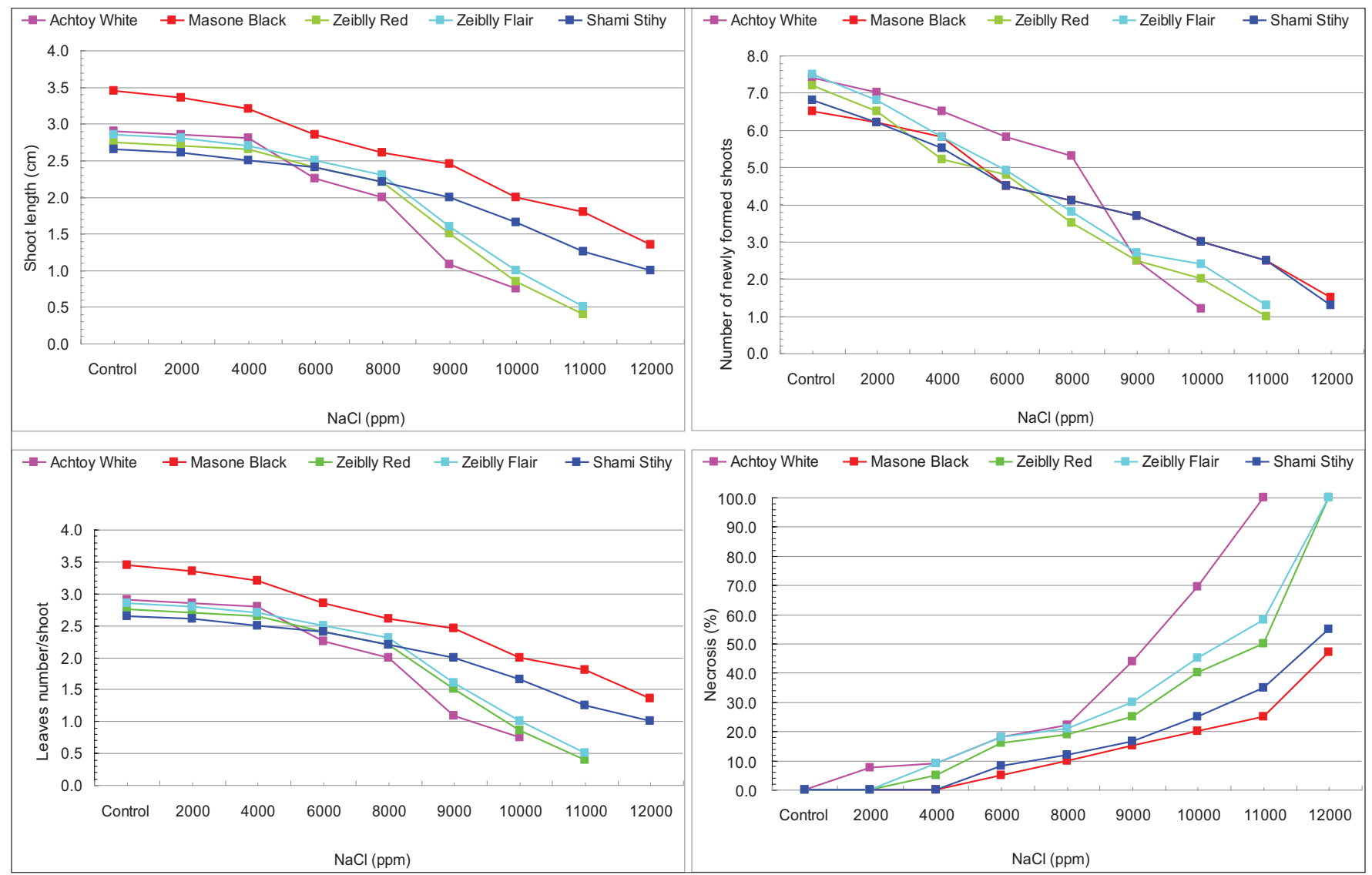

Fig. 1: Effect of different concentrations of $\mathrm{NaCl}$ on growth of in vitro cultured Ficus carica cvs. Achtoy White, Masone Black, Zeiblly Red, Zeiblly Flair, and Shami Stihy after 5 weeks of treatment. 
Table 4: Effect of different concentrations of $\mathrm{NaCl}$ on fresh weight and dry weight, chlorophyll contents of in vitro microshoots of $F$. carica cv. Achtoy White grown on MS medium supplemented with $3 \mathrm{mg} / \mathrm{L}$ BAP and $0.5 \mathrm{mg} / \mathrm{L} 2 \mathrm{iP}$ after 5 -week growth periods.

\begin{tabular}{|c|c|c|c|c|c|}
\hline $\mathrm{NaCl}$ (ppm) & Fresh weight/five explants (g) & Dry weight/five explant (g) & Chl a $(\mu \mathrm{g} / \mathrm{g}$ FW $)$ & Chl b $(\mu \mathrm{g} / \mathrm{g}$ FW $)$ & Chl a/b ratio \\
\hline Control & $3.55 \mathrm{a}$ & $1.87 \mathrm{a}$ & $252.89 \mathrm{a}$ & $98.85 \mathrm{a}$ & $2.56 \mathrm{a}$ \\
\hline 2000 & $3.37 \mathrm{~b}$ & $1.55 \mathrm{~b}$ & $242.70 \mathrm{~b}$ & $96.45 b$ & $2.51 \mathrm{~b}$ \\
\hline 6000 & $2.87 \mathrm{c}$ & $1.22 \mathrm{c}$ & $172.75 \mathrm{~d}$ & $82.40 \mathrm{~d}$ & $2.09 \mathrm{~d}$ \\
\hline 8000 & $2.00 \mathrm{~d}$ & $1.10 \mathrm{~d}$ & $125.60 \mathrm{e}$ & $65.95 \mathrm{e}$ & $1.90 \mathrm{e}$ \\
\hline 11000 & $0.00 \mathrm{~g}$ & $0.00 \mathrm{~g}$ & $0.00 \mathrm{~h}$ & $0.00 \mathrm{~h}$ & $0.00 \mathrm{~h}$ \\
\hline 12000 & $0.00 \mathrm{~g}$ & $0.00 \mathrm{~g}$ & $0.00 \mathrm{~h}$ & $0.00 \mathrm{~h}$ & $0.00 \mathrm{~h}$ \\
\hline
\end{tabular}

Mean followed by different letters differs significantly $(P<0.05)$. F carica: Ficus carica

Table 5: Effect of different concentrations of $\mathrm{NaCl}$ on fresh weight, dry weight, and chlorophyll contents of in vitro microshoots of $F$. carica cv. Masone Black grown on MS medium supplemented with $2 \mathrm{mg} / \mathrm{L} \mathrm{BA}$ and $0.5 \mathrm{mg} / \mathrm{L} 2 \mathrm{iP}$ after 5-week growth periods.

\begin{tabular}{|c|c|c|c|c|c|}
\hline $\begin{array}{l}\mathrm{NaCl} \\
(\mathrm{ppm})\end{array}$ & Fresh weight/five microshoots (g) & Dry weight/five mcroshoots (g) & Chl a $(\mu \mathrm{g} / \mathrm{g}$ FW $)$ & Chl b $(\mu \mathrm{g} / \mathrm{g}$ FW $)$ & Chl a/b ratio \\
\hline Control & $3.75 \mathrm{a}$ & $1.98 \mathrm{a}$ & $265.52 \mathrm{a}$ & $104.62 \mathrm{a}$ & $2.54 \mathrm{a}$ \\
\hline 4000 & $2.95 \mathrm{c}$ & $1.52 \mathrm{c}$ & $220.60 c$ & $90.05 \mathrm{c}$ & $2.45 b$ \\
\hline 6000 & $2.50 \mathrm{~d}$ & $1.39 \mathrm{~d}$ & $185.36 \mathrm{~d}$ & $81.30 \mathrm{~d}$ & $2.28 \mathrm{c}$ \\
\hline 8000 & $2.45 \mathrm{e}$ & $1.30 \mathrm{e}$ & $170.25 \mathrm{e}$ & $78.65 \mathrm{e}$ & $2.16 \mathrm{~d}$ \\
\hline 10000 & $2.15 \mathrm{~g}$ & $1.18 \mathrm{~g}$ & $92.45 \mathrm{~g}$ & $61.75 \mathrm{~g}$ & $1.50 \mathrm{f}$ \\
\hline 11000 & $1.95 \mathrm{~h}$ & $1.09 \mathrm{~h}$ & $85.75 \mathrm{~h}$ & $58.90 \mathrm{~h}$ & $1.45 \mathrm{f}$ \\
\hline 12000 & $1.85 \mathrm{i}$ & $1.04 \mathrm{i}$ & $67.40 \mathrm{i}$ & $49.78 \mathrm{i}$ & $1.35 \mathrm{~g}$ \\
\hline
\end{tabular}

Mean followed by different letters differs significantly $(P<0.05)$. F. carica: Ficus carica

Table 6: Effect of different concentrations of $\mathrm{NaCl}$ on fresh weight, dry weight, and chlorophyll contents of in vitro microshoots of $F$. carica cv. Zeiblly Red grown on medium supplemented with $2 \mathrm{mg} / \mathrm{L} \mathrm{BA}$ and $0.5 \mathrm{mg} / \mathrm{L} \mathrm{2iP} \mathrm{after} \mathrm{5-week} \mathrm{growth} \mathrm{periods.}$

\begin{tabular}{|c|c|c|c|c|c|}
\hline $\mathrm{NaCl}(\mathrm{ppm})$ & Fresh weight/five microshoots (g) & Dry weight/five microshoots (g) & Chl a $(\mu \mathrm{g} / \mathrm{g}$ FW) & Chl b $(\mu \mathrm{g} / \mathrm{g} \mathbf{F W})$ & $\mathrm{Chl} \mathrm{a/b} \mathrm{ratio}$ \\
\hline Control & $3.40 \mathrm{a}$ & $1.72 \mathrm{a}$ & $250.75 \mathrm{a}$ & $90.00 \mathrm{a}$ & $2.79 \mathrm{a}$ \\
\hline 2000 & $3.32 b$ & $1.61 b$ & $241.70 b$ & $87.50 \mathrm{~b}$ & $2.76 \mathrm{a}$ \\
\hline 4000 & $3.00 \mathrm{c}$ & $1.45 \mathrm{c}$ & $225.50 \mathrm{c}$ & $82.45 c$ & $2.73 \mathrm{a}$ \\
\hline 6000 & $2.75 d$ & $1.38 \mathrm{~d}$ & $210.90 \mathrm{~d}$ & $80.69 d$ & $2.61 b$ \\
\hline 8000 & $2.52 \mathrm{e}$ & $1.23 \mathrm{e}$ & $187.69 \mathrm{e}$ & $75.80 \mathrm{e}$ & $2.48 \mathrm{c}$ \\
\hline 9000 & $2.28 \mathrm{f}$ & $1.05 \mathrm{f}$ & $148.54 \mathrm{f}$ & $60.50 \mathrm{f}$ & $2.45 \mathrm{c}$ \\
\hline 10000 & $2.08 \mathrm{~g}$ & $0.92 \mathrm{~g}$ & $75.50 \mathrm{~g}$ & $55.78 \mathrm{~g}$ & $1.35 \mathrm{~d}$ \\
\hline 11000 & $1.87 \mathrm{~h}$ & $0.74 \mathrm{~h}$ & $70.00 \mathrm{~h}$ & $53.50 \mathrm{~h}$ & $1.30 \mathrm{~d}$ \\
\hline 12000 & $0.00 \mathrm{i}$ & $0.00 \mathrm{i}$ & $0.00 \mathrm{i}$ & $0.00 \mathrm{i}$ & $0.00 \mathrm{e}$ \\
\hline
\end{tabular}

Mean followed by different letters differs significantly $(P<0.05)$. F. carica: Ficus carica

and 1.49 when at $10000 \mathrm{ppm} \mathrm{NaCl}$ in cv. Zeiblly Red and Zeiblly Flair, respectively. The chlorophyll a and chlorophyll $\mathrm{b}$ amounts measured in the cultivars differed from one cultivar to another. At $\mathrm{NaCl} 12000$ ppm, leaves of Masone Black and Shami Stihy cultivars had the highest amounts of both chlorophyll a $(67.40$ and $55.89 \mu \mathrm{g} / \mathrm{g}$ FW.) and chlorophyll $\mathrm{b}(49.78$ and $40.98 \mu \mathrm{g} / \mathrm{g} \mathrm{FW})$ while the amounts of chlorophyll a and b were observed in Achtoy White cv $(90.80 \mu \mathrm{g} / \mathrm{g}$ FW and $55.95 \mu \mathrm{g} / \mathrm{g} \mathrm{FW}$ ) at $10000 \mathrm{ppm} \mathrm{NaCl}$, respectively. Moreover, the leaves contained chlorophyll a (70.00 and $82.35 \mu \mathrm{g} / \mathrm{g} \mathrm{FW})$ and chlorophyll b (53.50 and $55.00 \mu \mathrm{g} / \mathrm{g} \mathrm{FW}$ ) in the medium were observed contained the media 11000 ppm $\mathrm{NaCl}$ in Zeiblly Red and Zeiblly Flair cultivars, respectively. The decrease of chlorophyll content is a common symptom under salinity, and the higher ratio of Chla/Chlb was also considered to be the result of the decreased emphasis on light collection in relation to the rates of PSII photochemistry [9].

\subsubsection{Mineral analysis}

The effect of salinity levels on mineral contents of $F$. carica cvs. Achtoy White, Masone Black, Zeiblly Red, Zeiblly Flair, and Shami Stihy indicated an increasing of $\mathrm{Na}+, \mathrm{Cl}-$, and loss of $\mathrm{K}+$ ions contents 
Table 7: Effect of different concentrations of $\mathrm{NaCl}$ on fresh weight, dry weight, and chlorophyll contents of in vitro microshoots of $F$. carica cv. Zeiblly Flair grown on medium supplemented with $2 \mathrm{mg} / \mathrm{L} \mathrm{BA}$ and $0.5 \mathrm{mg} / \mathrm{L}$ after five-week growth periods.

\begin{tabular}{|c|c|c|c|c|c|}
\hline $\mathrm{NaCl}(\mathrm{ppm})$ & Fresh weight/five microshoots (g) & Dry weight/five microshoots (g) & Chl a $(\mu \mathrm{g} / \mathrm{g}$ FW $)$ & Chl b $(\mu \mathrm{g} / \mathrm{g}$ FW $)$ & $\mathrm{Chl} \mathbf{a} / \mathbf{b}$ ratio \\
\hline Control & $3.50 \mathrm{a}$ & $1.82 \mathrm{a}$ & $258.38 \mathrm{a}$ & $94.30 \mathrm{a}$ & $2.74 \mathrm{a}$ \\
\hline 2000 & $3.41 \mathrm{~b}$ & $1.68 \mathrm{~b}$ & $244.20 \mathrm{~b}$ & $89.70 \mathrm{~b}$ & $2.72 \mathrm{a}$ \\
\hline 6000 & $2.75 d$ & $1.42 \mathrm{~d}$ & $220.30 d$ & $83.75 \mathrm{~d}$ & $2.63 b$ \\
\hline 8000 & $2.64 \mathrm{e}$ & $1.37 \mathrm{e}$ & $194.50 \mathrm{e}$ & $78.60 \mathrm{e}$ & $2.47 \mathrm{c}$ \\
\hline 11000 & $1.92 \mathrm{~h}$ & $0.98 \mathrm{~h}$ & $82.35 \mathrm{~h}$ & $55.00 \mathrm{~h}$ & $1.49 \mathrm{~d}$ \\
\hline 12000 & $0.00 \mathrm{i}$ & $0.00 \mathrm{i}$ & $0.00 \mathrm{i}$ & $0.00 \mathrm{i}$ & $0.00 \mathrm{e}$ \\
\hline
\end{tabular}

Mean followed by different letters differs significantly $(P<0.05)$. F. carica: Ficus carica

Table 8: Effect of different concentrations of $\mathrm{NaCl}$ on fresh weight, dry weight, and chlorophyll contents of in vitro microshoots of $F$. carica cv. Shami Stihy grown on medium supplemented with $3 \mathrm{mg} / \mathrm{L}$ BAP and $0.5 \mathrm{mg} / \mathrm{L} 2 \mathrm{iP}$ after 5 -week growth periods.

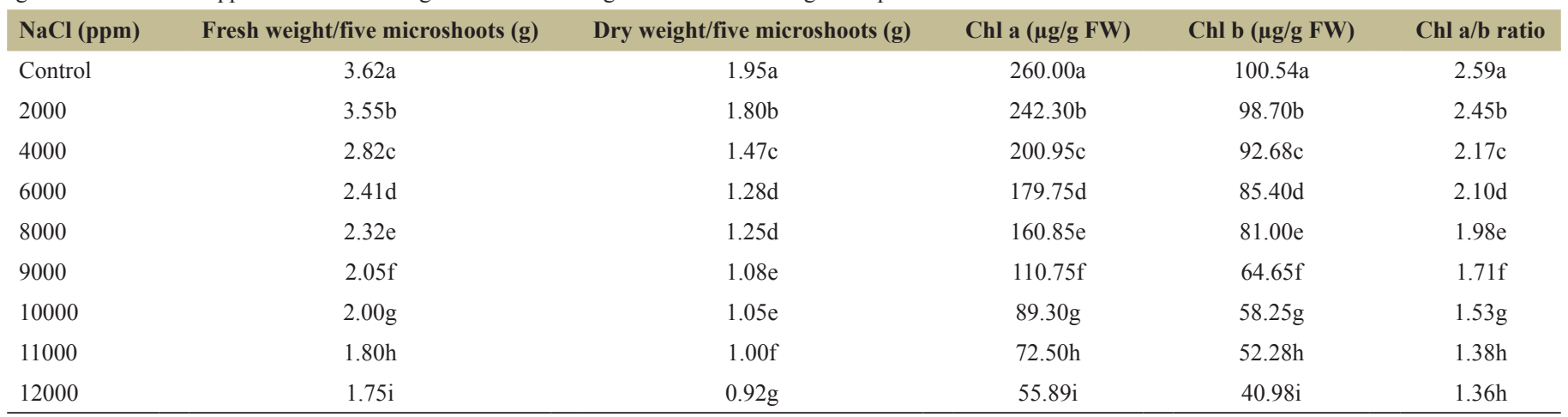

Mean followed by different letters differs significantly $(P<0.05)$. F. carica: Ficus carica

with increasing salinity concentrations. When the sodium chloride concentration increased, the level of $\mathrm{K}+$ decreased in the shoots and roots of the studied cultivars. Results can be explained on the basis that the increase of sodium ion is compensated for the loss of potassium ion [29]. The value obtained in the roots was lower than that of the shoots. The study showed that with the increased concentration of $\mathrm{NaCl}$, increased $\mathrm{Na}+$ and $\mathrm{Cl}$ - contents in shoots and roots and low $\mathrm{K}+$ content in all cultivars. The analysis of $\mathrm{K}+$ content results showed that the treatments at $4000,6000,8000,10000$, and $12000 \mathrm{ppm}$ of $\mathrm{NaCl}$ were differed significantly from the control treatment. The lowest $\mathrm{K}+$ content was recorded with the highest concentration of $\mathrm{NaCl}(12000 \mathrm{ppm})$ with all cultivars. The highest $\mathrm{Na}+$ content was detected at this concentration in all cultivars, and this value differed from one cultivar to another. $\mathrm{Na}+$ content in shoots of Masone Black and Shami Stihy cultivars was significantly lower than $\mathrm{Na}+$ content in the other cultivars. Through these results obtained, it can be concluded that Masone Black and Shami Stihy cultivars were the most salt stress tolerant due to its less $\mathrm{Na}+$ absorption and more $\mathrm{K}+$ accumulation in roots compared with the other cultivars (Fig. 2). In addition, according to results showed in Fig. 3, $\mathrm{K}+/ \mathrm{Na}+$ ratio was the highest in Masone Black and Shami Stihy cultivars, especially at the highest salt stress, which was 0.14 in shoots and 0.15 in roots of Masone Black cultivar and 0.13 in shoots and 0.14 in roots of Shami Stihy cultivar compared with Achtoy White, Zeiblly Red and Zeiblly Flair cultivars which was lowest in $\mathrm{K}+/ \mathrm{Na}+$ ratio when the highest salt stress concentration was applied. This trait has a potential value as selection standard for salt stress [30]. In this study, internal concentrations of $\mathrm{Na}+$ and $\mathrm{Cl}$ - were increased with increasing external $\mathrm{NaCl}$ concentration in all fig cultivars, and the selected
Masone Black and Shami Stihy cultivars accumulated more $\mathrm{Na}+$ and $\mathrm{Cl}$ - than Achtoy White, Zeiblly Red, and Zeiblly Flair cultivars. There are many interactions between these elements, and these interactions depend on the salinity level and composition of salts, the crop species, the nutrient in question, and a number of environmental factors [31]. Similar observations regarding internal $\mathrm{Na}+$ and $\mathrm{Cl}$ - content for $\mathrm{NaCl}$ tolerant were observed with tomatoes [32]. The concentration of salt increases, the ability to exclude salt may become less effective in protecting the plant from salt stress, and other mechanisms, such as osmotic tolerance, may become increasingly important. Furthermore, potassium was lower in $\mathrm{NaCl}$-adapted calli of potato with the increase in the external salt concentration up to $250 \mathrm{mM} \mathrm{NaCl}$ exposed to salt than in non-adapted calli grown in standard medium [33].

\subsubsection{Proline content}

Proline content increased with the increases in $\mathrm{NaCl}$ level of all cultivars (Fig. 4). The highest proline content ( 85.45 and $82.00 \mu \mathrm{g} / \mathrm{g} \mathrm{FW}$ ) was obtained at $12000 \mathrm{ppm} \mathrm{NaCl}$ of fig cvs. Masone Black and Shami Stihy, respectively, and was obtained (74.5 and $76.0 \mu \mathrm{g} / \mathrm{g} \mathrm{FW})$ at $11000 \mathrm{ppm}$ $\mathrm{NaCl}$ of Zeiblly Red and Zeiblly Flair cultivars, respectively, while cv. Achtoy White was obtained $(62.30 \mu \mathrm{g} / \mathrm{g} \mathrm{FW})$ which the lowest in proline content when the highest salt stress concentration was applied. Several studies have shown that treatment of plants with high concentrations of sodium chloride caused an increase in proline content in Phoenix dactylifera callus [34]; Carrizo citrange [35]; Saccharum sp. Callus [36]; and Phaseolus vulgaris L. callus [37]. Furthermore, the proline content in tissues increased with increased salt stress fig cvs. Black Mission, Brown Turkey, and Brunswick [7]. 


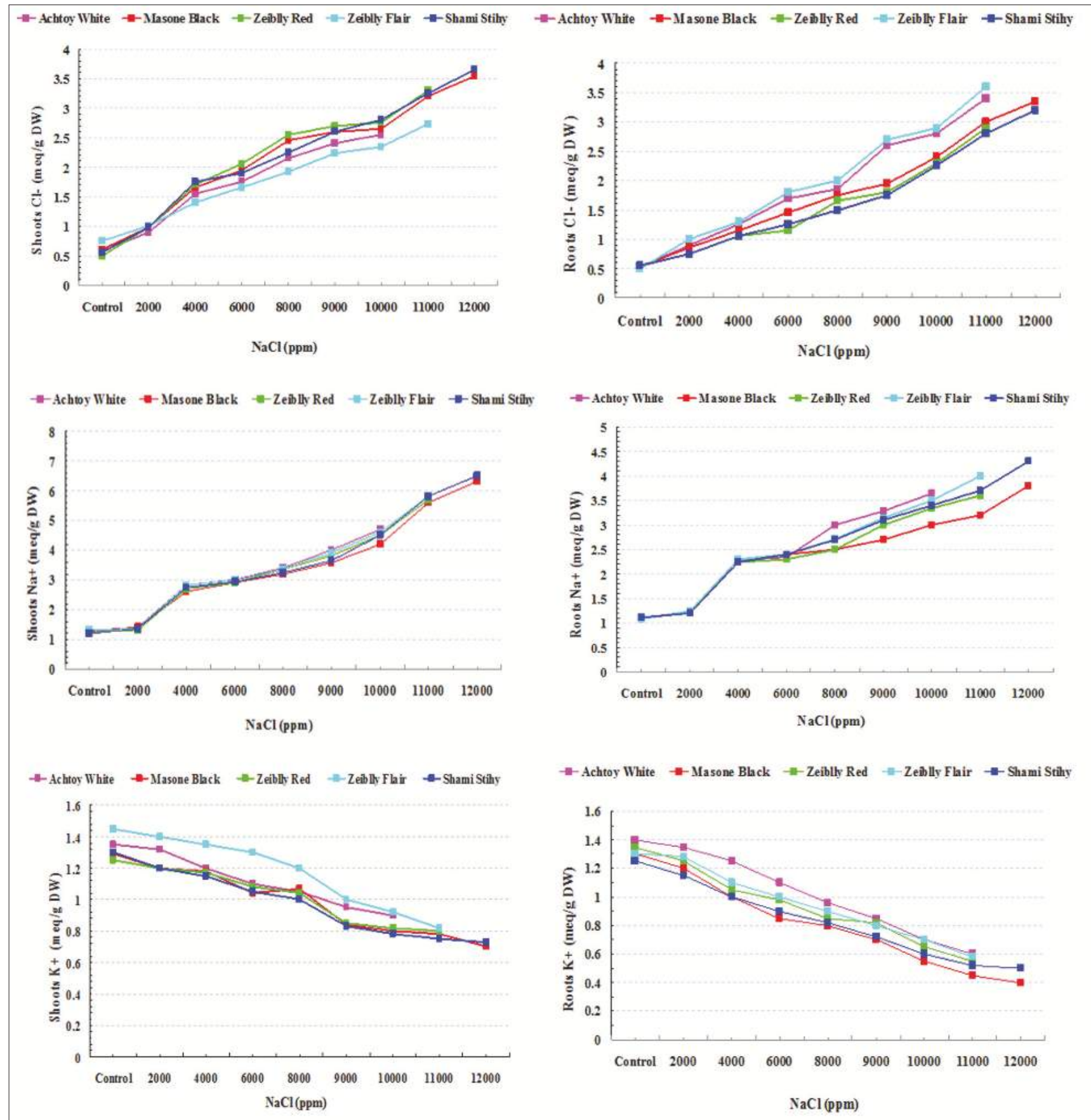

Fig. 2: $\mathrm{K}+, \mathrm{Na}^{+}$, and $\mathrm{Cl}$ - concentrations (milliequivalents per gram DW) in roots and shoots of five Ficus carica cultivars Achtoy White, Masone Black, Zeiblly Red, Zeiblly Flair, and Shami Stihy during 60 days with water containing 0.0, 2000, 4000, 6000, 8000, 10000, 11000, and12000 ppm NaCl.

\section{CONCLUSION}

We investigated the five $F$. carica cultivars, cultured in vitro, to grow under different $\mathrm{NaCl}$ concentrations. After treating the plantlets to different concentrations of $\mathrm{NaCl}$ for 8 months, morphological and physiological parameters were recorded. The growth of plant on both multiplication and rooting stages was gradually decreased by increasing $\mathrm{NaCl}$ levels. As salt stress intensified, there was a reduction in shoot length, formed shoots, and fresh and dry weights. The study showed that with the increase of the $\mathrm{NaCl}$ concentration in all studied parameters decrease while the $\mathrm{Na}+$ and $\mathrm{Cl}$ - content increases in the all cultivars. $\mathrm{Na}+$ and $\mathrm{Cl}-$ in plant tissues of all cultivars increased while $\mathrm{K}+$ decreased with the increase of salt concentrations. Masone Black and Shami Stihy cultivars had a higher tolerance to salinity compared with other cultivars. The results of this study showed the possibility of using tissue culture in the evaluation of fig salt tolerance under certain environmental conditions in a short time.

\section{ACKNOWLEDGMENTS}

The authors would like to thank all the research team in the Tissue Culture and Biotechnology Laboratories, Maryout Research Station, Desert Research Center, Egypt. 


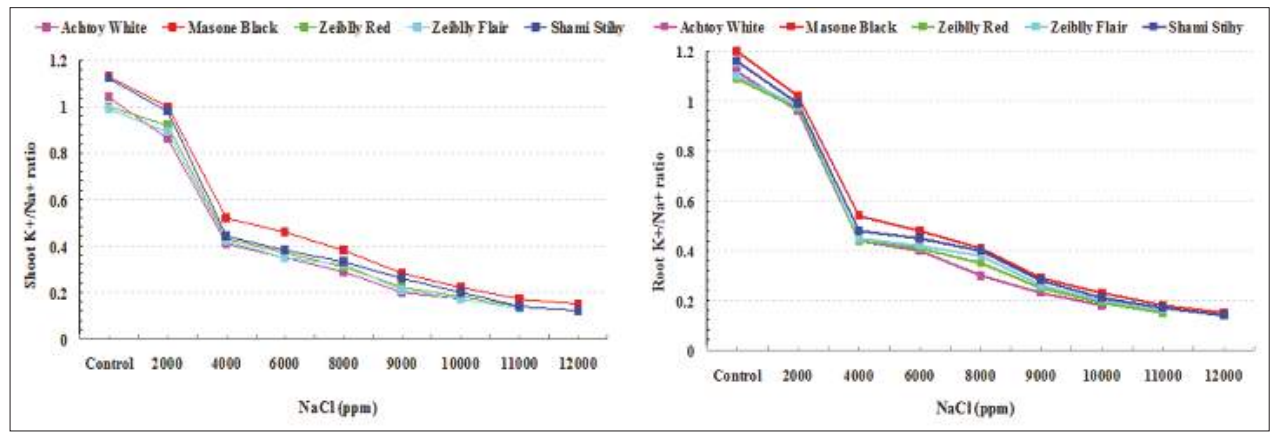

Fig. 3: Effect of $\mathrm{NaCl}(0,2000,4000,6000,8000,10000,11000$, or 12000 ppm) on shoot and roots $\mathrm{K}+/ \mathrm{Na}+$ ratio in Ficus carica cultivars Achtoy White, Masone Black, Zeiblly Red, Zeiblly Flair, and Shami Stihy.

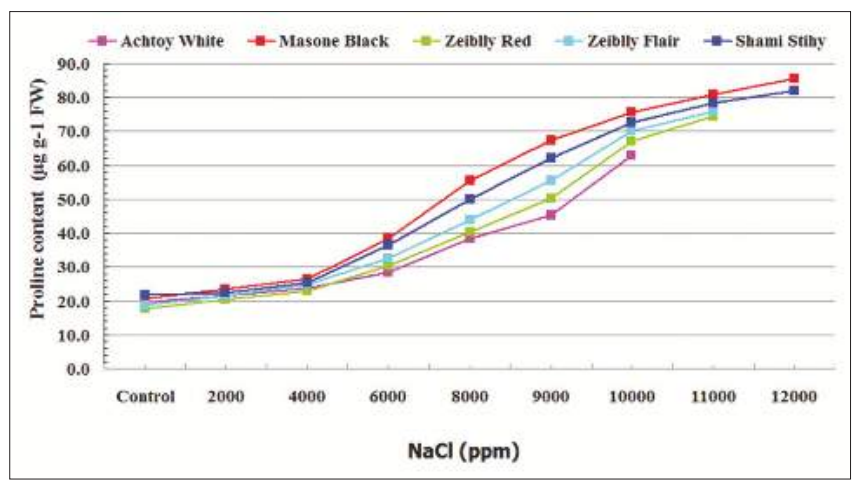

Fig. 4: Effects of different level of $\mathrm{NaCl}$ on proline content of grown Ficus carica cultivars Achtoy White, Masone Black, Zeiblly Red, Zeiblly Flair, and Shami Stihy during 60 days with water containing 0.0, 2000, 4000, 6000, $8000,10000,11000$, and $12000 \mathrm{ppm} \mathrm{NaCl}$.

\section{REFERENCES}

1. Watson L, Dallwitz MJ. The Families of Flowering Plants: Descriptions, Illustrations, Identification, and Information Retrieval. Available from: http://www.biodiversityunoedu/delta. [Last accessed on 2004 Jun].

2. Tous J, Ferguson L. In: Janick J, editor. "Mediterranean Fruits," in Progress in New Crops. Arlington, Va, USA: ASHS Press; 1996. p. 416-30.

3. Neal MC. In: Gardens of Hawaii. Vol. 40. Honolulu, Hawaii, USA: University of Hawaii and Bishop Museum; 1965.

4. Zohary D, Hopf M. Domestication of Plants in the Old World. $3^{\text {rd }}$ ed. New York: Oxford University, Press; 2000.

5. Mars M. Fig (Ficus carica L.) genetic resources and breeding. Acta Hortic 2003;605:19-27.

6. Howladar S. A novel Moringa oleifera leaf extract can mitigate the stress effects of salinity and cadmium in bean (Phaseolus vulgaris L.) plants. Ecotoxicol Environ Saf 2014;100:69-75.

7. Ehab MM, Soliman HI, Al-Zahrani HS, Howladar SM, Fuller MP. Influence of different concentrations of salt stress on in vitro multiplication of some fig (Ficus Carcia L.) cultivars. Life Sci J 2014;11:386-97.

8. Essam M, Mohamad M, Zakaria I. Effect of different concentration of carbon source, salinity and gelling agent on in vitro growth fig (Ficus carica L.). Afr J Biotechnol 2013;12:936-40.

9. Ruan H, Shen W, Xu L. Nitric oxide modulates the activities of plasma membrane $\mathrm{H}+\mathrm{ATPase}$ and PPase in wheat seedling roots and promotes the salt tolerance against salt stress. Acta Botanica Sinica 2004;46:147-50.

10. Luttus S, Kinet M, Bouhartmont J. Effect of various salts and of mannitol on ion and proline accumulation in relation to osmotic adjustment in rice (Oryza sativa L.) callus culture. J Plant Physiol 1999;149:186-95.

11. Shatnawi M, Faouri A, Al-Mazraawi M, Shibli R, Makhadmeh I. Tissue culture and salt stress in Chrysanthemum morifolium. Acta Hortic 2009;829:189-96.

12. Shatnawi M, Johnson K, Torpy F. In vitro propagation and cryostorage of Syzygium francisii (Myrtaceae) by encapsulation-dehydration method. In vitro Cell Dev Biol 2004;40:403-7.

13. Shatnawi M, Shibli RA, Abu-Romman SM, Al-Mazra'awi MS, Al-Ajlouni ZI, Shatanawi WA, et al. Clonal propagation and cryogenic storage of the medicinal plant Stevia rebaudiana Span. J Agric Res 2011a;9:213-20.

14. Chebet K, Okeno A, Mathenge P. Biotechnological approaches to improve horticultural crop production. Acta Hortic 2003;625:473-7.

15. Soliman HI, Mahdia FG, Naglaa AA. Efficient transformation and regeneration of fig (Ficus carica L.) via somatic embryogenesis. GM Crops Food 2010;1:42-53.

16. Shatnawi M, Anfoka G, Shibli R, Al-Mazra'awi M, Shahrour W, Arebia A. Clonal propagation and cryogenic storage of virus free grapevine (Vitis vinifera L.) via meristem culture. Turk J Agric For 2011b;35:173-84.

17. Chaohong F, Renrui W, Jingwei L, Biao W, Zhenfang Y, Zhenhua C, et al. Production of pathogen-free horticultural crops by cryotherapy of in vitro grown shoot tips. Methods Mol Biol 2013;994:463-48.

18. Soliman HI. Tissue Culture Technique for Production of Virus-Free Fig and Its in vitro Preservation. M.Sc. Thesis, Faculty of Agriculture Cairo University 2000. p. 145.

19. Murshige T, Skoog F. A revised medium for growth and bioassay with tobacco tissue cultures. Physiologia Plantarum 1962;15:473-97.

20. Chapman HD, Pratt PF. Method of Analysis for Soil Plants and Water. California: University of California; 1961. p. 169-70.

21. De Filippis LF, Hampp R, Ziegler H. The effects of sub lethal concentrations of zinc, cadmium and mercury on Euglena. II. Respiration, photosynthesis and photochemical activities. Arch Microbiol 1981;128:407-11.

22. Anderson JM, Boardman NK. Studies on the greening of dark grown bean plants II. Development of photochemical activity. Aust J Biol Sci 1964;17:93-101.

23. Bates L, Waldren RP, Teare ID. Rapid determination of free proline for water-stress studies. Plant Soil 1973;39:205-7.

24. Snedecor G, Cocharn W. Statistical Methods. $6^{\text {th }}$ ed. Ames, Iowa, U.S.A: Iowa State University, Press; 1967.

25. Murithii LM, Rangan TS, Waite BH. In vitro propagation of fig through shoot tip culture. Horti Sci 1982;17:86-7.

26. Pontikis CA, Melas P. Micropropagation of Ficus carica L. Hortic Sci 1986;21:153.

27. Sayed R, Mohammad G, Maryam R. The interaction of zinc with 
other elements in plants: Review. Int J Agric Crop Sci 2012;4:1881-4.

28. Kasuga M, Liu Q, Miura S, Shinozaki KY, Shinozaki K. Improving plant drought, salt, and freezing tolerance by gene transfer of a single stress-inducible transcription factor. Nat Biotechnol 1999;17:287-91.

29. Kumar N, Pamidimarri SD, Kaur M, Boricha G, Reddy MP. Effects of $\mathrm{NaCl}$ on growth, ion accumulation, protein, proline contents and antioxidant enzymes activity in callus cultures of Jatropha curcas. Biologia 2008;63:378-82.

30. Grattan S, Grieve M. Salinity-mineral nutrient relations in horticultural crops. Sci Hortic 1999;78:127-57.

31. Greenway H, Munns R. Mechanisms of salt tolerance in nonhalophytes. Ann Rev Plant Physiol 1980;31:149-90.

32. Tal M, Heinkin H, Dehan K. Salt tolerance of the cultivated tomato: Responses of callus tissue of Lycopersicon esculentum, L. peruvianum and Solanum penellii to high salinity. Z Pflanzenphysio 1978;86:231-40.

33. Sabbah S, Tal M. Development of callus and suspension cultures of potato resistant to $\mathrm{NaCl}$ and mannitol and their response to stress. Plant Cell, Tissue and Organ Culture 1990;21:119-28.
34. Al-Khayri JM. Growth proline accumulation and ion content in sodium chloride stressed callus of date palm. In Vitro Cell Dev Biol Plant 2002;38:79-82.

35. Arbona V, Flors V, Jacas J, Garc'ia-Agustı'n P, Go'mez-Cadenas A. Enzymatic and non-enzymatic antioxidant responses of carrizo citrange, a salt-sensitive citrus rootstock, to different levels of salinity. Plant Cell Physiol 2003;44:388-94.

36. Errabii T, Gandonou CB, Essalman H, Abrin J, Idaomar M, Senhaji NS. Effects of $\mathrm{NaCl}$ and mannitol induced stress on sugarcane (Saccharum sp.) callus cultures. Acta Physiol Plant 2007;29:95-102.

37. Stoeva N, Kaymakanova M. Effect of salt stress on the growth and photosynthesis rate of bean plants (Phaseolus vulgaris L.). J Cent Eur Agr 2008;9:385-92.

\section{How to cite this article:}

Soliman HIA, Alhady MRAA. Evaluation of salt tolerance ability in some fig (Ficus carica L.) cultivars using tissue culture technique. J App Biol

Biotech. 2017;5(6):29-39. DOI: 10.7324/JABB.2017.50605 